\title{
Do manufacturers of brand-name drugs engage in price competition? An analysis of introductory prices
}

\section{Joel Lexchin}

M ost new drugs that reach the market do not offer any significant therapeutic gain over existing products. ${ }^{1,2}$ Critics of the pharmaceutical industry have argued that these "me-too" drugs are a needless waste of resources. It can take hundreds of millions of dollars to develop them and many more millions to promote them.

One justification offered for having these me-too drugs is that they create price competition within their therapeutic class. Lee ${ }^{3}$ and DiMasi ${ }^{4}$ compared prices of first-in-class drugs in the United States with prices of drugs introduced later in the same class and showed that, in some cases, products introduced later were priced substantially lower than the drug first introduced in the class. New drugs that are of limited therapeutic benefit are introduced at relatively low prices, and then their prices are raised in subsequent years, a practice known as penetration pricing. 5,6

The US pharmaceutical environment is substantially different from Canada's in a number of respects. In the United States, drug manufacturers are free to set their own introductory prices. There are multiple markets, each with its own prices (the undiscounted retail market for those without drug insurance, markets with government controls such as Medicaid and the Veterans Health Administration, and markets controlled by Pharmacy Benefit Managers that negotiate price discounts for the patient populations that they cover).

In Canada, the federal Patented Medicine Prices Review Board (PMPRB) divides patented "new active substance" (NAS) products - drugs never marketed in Canada in any form - into 2 categories: those that are breakthrough products or that offer major therapeutic benefits and those that offer moderate, little or no additional therapeutic benefits over existing drugs. Products in the latter category have their introductory prices limited to that of the most expensive existing product in the therapeutic class; thereafter, prices can increase only at the rate of inflation. Because of PMPRB regulations, there tends to be a uniform Canadian price rather than separate prices for different markets. ${ }^{7}$ In addition, some provinces have imposed price freezes for drugs in their formularies.

Because of the differences between the US and Canadian markets, drug manufacturers in Canada may adopt pricing strategies different from those used in the United States. I undertook this study to examine whether there is price competition between new and existing brand-name drugs in therapeutic classes in which the new product offers no significant benefit over the existing products in terms of safety or efficacy.

I manually searched the annual reports of the PMPRB from 1994 to 2003 and recorded the names of all NAS products evaluated by the PMPRB. Using the World Health Organization's Collaborating Centre for Drug Statistics Methodology (www.whocc .no/atcddd) and 4 reference sources (the Australian Medicines Handbook, ${ }^{8}$ the Oregon Health and Science University's Drug
Effectiveness Review Project [www.ohsu.edu/drugeffectiveness], the Canadian Pharmacists Association's Therapeutic Choices ${ }^{9}$ and issues of Treatment Guidelines from The Medical Letter), I evaluated each product to see if it was therapeutically equivalent to drugs already marketed in Canada. Using data from provincial formularies, I compared daily treatment costs for new medications with the mean price of existing drugs in the same class and with the price of the most expensive competitor in the class. If existing drugs were available in both brand and generic forms, only the price of the brand-name drug was used.

Of an initial list of 212 NAS products, 33 drugs in 16 therapeutic classes were available for analysis. Appendix I (available online at www.cmaj.ca/cgi/content/full/I74/8/II20/DCI) lists each drug and the year it was assessed by the PMPRB, the drugs I used for price comparison, the therapeutic class and the main indication.

The mean introductory price of the 33 new medications was $95.9 \%$ of the price of existing brand-name products and 9I. $5 \%$ of the price of the most expensive brand-name product in their class. Most of the new drugs were introduced at prices that were near or equal to the mean price of the existing brand-name products in their therapeutic class (Fig. I). Only 2 of the new drugs were introduced at substantial discounts $(>30 \%$ ) compared with the mean price of their competitors.

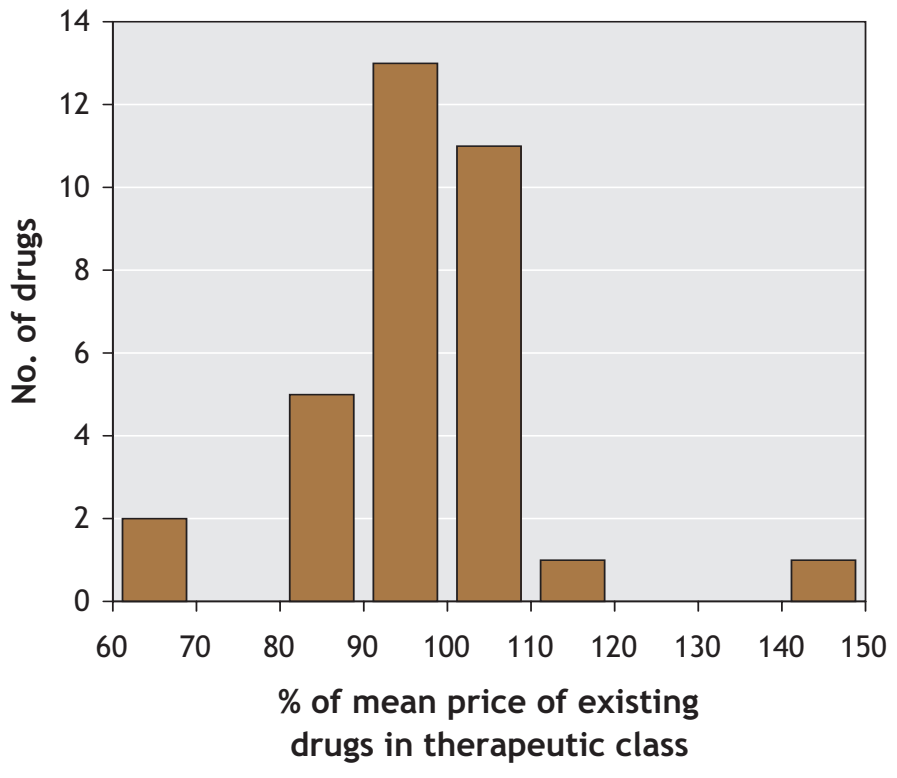

Fig. 1: Distribution of 33 new drugs by how their introductory prices related to the mean price of existing brand-name drugs in their therapeutic class. 
For new products marketed between 1994 and 1998 and those marketed between 1999 and 2003, there was no statistically significant difference in either period between the introductory prices and the mean price of existing drugs in the same class or the price of the most expensive produce in the same class. Unlike previous studies from the United States ${ }^{5}$ and Sweden ${ }^{10}$ that suggested a difference in introductory prices between drugs primarily intended for acute conditions and those primarily intended for chronic conditions, I found no such difference in the Canadian data. In the comparison of introductory prices of the new drugs and the prices of the most expensive existing products in their class, the prices of the new drugs were significantly lower when there were 4 or more competitors in the class than when there were I- 3 competitors, a finding similar to that of $\mathrm{Lu}$ and Comanor in the United States. ${ }^{5}$

This study showed that pharmaceutical companies that introduced new patented brand-name drugs in Canada between I994 and 2003 did not compete on price with existing products in the same class, except when there were 4 or more competitors. The lack of price competition was evident even for drugs used to treat acute or chronic conditions. Since price competition did not occur at the introduction of new drugs offering little or no therapeutic benefit over existing medications, it is unlikely that it existed in other situations.

Prices of some of the new products were higher than those of the most expensive competitor. Under the PMPRB regulations, this situation should not have existed. However, the products chosen for comparison in this study may not have been the same ones that the PMPRB used to determine whether introductory prices were excessive.

In some of the many US markets, price competition at introduction does exist for drugs that offer little additional therapeutic value over existing ones, but the prices for these new products tend to rise over subsequent years ${ }^{5,6}$ such that the overall benefits from price competition may not be that great. Introductory prices of drugs that offer major therapeutic benefits are 3 times greater on average than the prices of existing drugs, but they tend to decrease over time. ${ }^{5}$ Despite these forms of price competition in some US markets, the overall gap in prices of patented brand-name drugs between the United States and Canada has been widening: in 1997 prices in the United States were $56 \%$ higher on average than those in Canada, and in 2004 they were almost $79 \%$ higher. ${ }^{2}$ Therefore, price competition does not seem to have the same effect as do the price restrictions imposed by the PMPRB and the provinces.

In this study, some degree of price competition was observed when there were 4 or more competitors in a therapeutic class, but this situation existed for only 7 of the 33 new products reviewed. Questions remain as to whether more pharmaceutical companies would compete in certain markets if freer pricing were allowed and how great the benefits of that competition would be.

Current PMPRB regulations allow pharmaceutical companies to set the price of new drugs that offer no major therapeutic benefits over existing ones in their class up to the maximum price of existing drugs in the same class. Prescriptions for newer medications are one of the main driving forces behind the rapid escalation of drug expenditures in Canada. ${ }^{11}$ From 1997 to 200I, the price of a prescription for a patented medication in Ontario, excluding the dispensing fee, increased $6.2 \%$ annually, to $\$ 84.36$ on average in 200I. ${ }^{12}$ Altering the PMPRB pricing regulations for products that offer no additional therapeutic benefit could lower prices in these therapeutic classes and help to control escalating drug expenditures.

Until now, provincial governments have been reluctant to use their substantial purchasing power to achieve lower prices, except for the use of reference-based pricing in British Columbia. Under this system the BC government fully covers the cost of only the least expensive product in the therapeutic class. At present, the BC system includes only 5 therapeutic classes. Other provinces could adopt reference-based pricing and expand it to include additional classes. Moreover, rather than provinces acting unilaterally, they could act in concert to achieve significant savings.

This article has been peer reviewed.

Joel Lexchin is Associate Professor at the School of Health Policy and Management, York University, is with the Emergency Department, University Health Network, and is Associate Professor in the Department of Family and Community Medicine, University of Toronto, Toronto, Ont.

Competing interests: None declared.

Acknowledgement: I thank Albert Banerjee for his help in gathering the raw data for this study.

\section{REFERENCES}

I. A review of new drugs in 2004: floundering innovation and increased risk-taking. Prescrire Int 2005; 14 :68-73.

2. Patented Medicine Prices Review Board (PMPRB). Annual report 2004. Ottawa: PMPRB; 2005.

3. Lee TH. "Me-too" products - Friend or foe? [published erratum in N Engl J Med 2004;350(I5):I586]. N Engl J Med 2004;350:2II-2.

4. DiMasi JA. Price trends for prescription: pharmaceuticals: 1995-1999. Background report prepared for the US Department of Health and Human Services' Conference on Pharmaceutical Pricing Practices, Utilization and Costs; 2000 Aug 8-9; Washington, DC. Available: http://aspe.hhs.gov/health/reports/Drug-papers/dimassi/dimasi-final.htm (accessed 2006 Mar 6).

5. Lu ZJ, Comanor WS. Strategic pricing of new pharmaceuticals. Rev Econ Stat I998;80:I08-I8.

6. Reekie WD. Price and quality competition in the United States drug industry. I Ind Econ $1978 ; 26: 223-37$.

7. Inter-provincial prescription drug price comparison 1995/96-1999/00. Prepared by the Patented Medicine Prices Review Board for the Federal/Provincial/Territorial Working Group on Drug Prices. Available: www.pmprb-cepmb.gc.ca/CMFiles /comparison-eI4HFB-492003-9884.pdf (accessed 2006 Mar 6).

8. Rossi S, editor. Australian medicines handbook. Adelaide: Australian Medicines Handbook Pty Ltd; 2002.

9. Gray J, editor. Therapeutic choices. $4^{\text {th }}$ ed. Ottawa: Canadian Pharmacists Association; 2003.

Io. Ekelund M, Persson B. Pharmaceutical pricing in a regulated market. Rev Econ Stat 2003;85:298-306.

II. Federal/Provincial/Territorial Working Group on Drug Prices. Cost driver analysis of provincial drug plans: Ontario I992/93-I998/99. Ottawa: The Working Group; 2000. Available: www.pmprb-cepmb.gc.ca/CMFiles/on-er4HNL-492003-44I3.pdf (accessed 2006 Mar 6).

I2. Analysis of drug claim costs I997-200I. Toronto; Green Shield Canada; 2003.

Correspondence to: Dr. Joel Lexchin, I2I Walmer Rd., Toronto ON M5R 2X8; fax 416-736-5227; joel.lexchin@utoronto.ca or jlexchin@yorku.ca 